\title{
Effects of Stimulus Presentation Method on Discourse Comprehension in Healthy Elderly Adults
}

\author{
JeHo Song ${ }^{\mathrm{a}}$, Hyunjoo Choi $^{\mathrm{b}}$ \\ ${ }^{a}$ Buldang Hana 365 Clinic, Cheonan, Korea \\ ${ }^{b}$ Department of Communication Disorders, Korea Nazarene University, Cheonan, Korea
}

Correspondence: Hyunjoo Choi, PhD

Department of Communication Disorders, Korea Nazarene University, 48 Wolbong-ro, Seobuk-gu, Cheonan 31172, Korea

Tel: +82-41-570-1677

Fax: $+82-41-570-7846$

E-mail: hjchoi@kornu.ac.kr

Received: July 5, 2020

Revised: August 11, 2020

Accepted: August 11, 2020

This work is based on the master's thesis of the first author.

\begin{abstract}
Objectives: Although the ability of discourse comprehension in the elderly may vary depending on the method of stimulus presentation, relevant research into this topic is limited. The purpose of this study was to examine the differences in ability of discourse comprehension in healthy elderly adults according to the discourse stimulus presentation method, and to determine whether the effects of the discourse stimulus presentation method are different depending on the question type; for example literal information or inference. Methods: Forty-eight healthy elderly adults participated in this study. To examine the ability of discourse comprehension, a recall task was used to listen to the story and answer the questions. As methods of presenting discourse stimulus, telling a story once, telling it twice, and presenting it with a picture were used. The question types consisted of the literal information (LI), text-connecting inference (TC) and gap-filling inference (GF) types. Results: First, the discourse comprehension scores were higher in telling a story twice and presenting it with a picture than in telling a story once. Second, performance of $\mathrm{LI}$ was the highest in telling a story twice, while performance of TC was the highest in presenting story with a picture. Third, in the case of GF, the difference in ability of discourse comprehension according to the stimulus presentation method was not significant. Conclusion: These results suggest that it is more effective to present the discourse repeatedly to improve the superficial comprehension of discourse for the healthy elderly, and visual stimulus to improve logical reasoning for connection and integration between texts.
\end{abstract}

Keywords: Discourse comprehension, Stimulus presentation, Repetition, Visual stimulation
자연스러운 노화과정에서 주의력(attention), 기억력(memory), 집행기능(executive function) 등의 인지 기능 저하가 나타나고, 이 러한 인지적 노화는 노인의 언어 기능 변화와 밀접한 관련이 있다 (Schaie \& Willis, 2010). 이에 노화로 인한 인지 능력의 변화에 관련 된 연구는 최근 활발히 이루어지고 있으며, 의사소통 능력의 저하 와 관련된 연구 역시 다양화되고 있다. 노화로 인한 의사소통 문제 와 관련된 연구는 언어이해 보다는 언어표현 능력에 초점이 맞춰져 있고, 언어이해 관련 연구 중에서도 단어나 문장이해 능력에 비해 담화이해와 관련된 연구는 부족한 실정이다(Kim \& Kim, 2009). 그러나 실제 일상생활 속에서의 상호작용을 위하여 가장 많이, 자 연스럽게 사용되는 의사소통 형태는 담화이며(Stubbs, 1983), 따라
서 담화 능력에 관련된 연구는 매우 중요하다(Sparks, 2012). 담화 능력 중 담화이해는 메시지의 해독(decoding)을 위한 언어 기능, 텍스트 이해를 위한 주의력, 담화의 구조를 이해하고 스토리 를 구성하는 기억력, 작업기억(working memory) 및 집행기능 등 다양한 인지 능력을 요구하며(Light, 1991), 이러한 복잡하고 통합 적인 과정을 포함하기 때문에 노화 과정에서 담화이해 능력의 저하 가 나타난다(Ferstl, Walther, Guthke, \& von Cramon, 2005; Son \& Kang, 2006). 특히, 정보처리 속도의 제한, 주의력 및 작업기억 능력 의 저하가 언어이해와 회상(recall)을 필요로 하는 담화이해와 밀접 한 관련이 있는 것으로 알려져 있다(Kemper, 2006). 담화이해 능력 의 변화는 노인들의 주관적인 호소로도 나타나는데, 노인들은 대 
화 참여의 어려움, 청각적 지시 따르기의 곤란, 질문을 확인하기 위 한 반복 질문, 대화 주제 변화에 따른 이해의 어려움 등에 문제가 있 다고 보고하였다(Burda, 2010). 일반 노인을 대상으로 한 담화이해 연구들을 살펴보면 60대에서는 담화이해 능력이 비교적 양호하나 70대 이상에서 저하가 나타나며(Lee, Lee, Song, \& Kim, 2014), 특 히, 청각적 처리과정의 지연(delay)이 담화이해의 어려움으로 작용 하는 것으로 알려져 있다(Little, Prentice, Darrow, \& Wingfield, 2005).

노인의 담화이해 능력은 질문유형에 따라 저하 양상이 다른 것 으로 알려져 있다(Kim \& Choi, 2015). 질문유형에 따른 일반 노인 의 담화이해 능력을 평가한 Kim과 Choi (2015)의 연구에 따르면 담화에 표면적으로 명시되어 있는 정보를 이해해야 하는 사실적 정보이해(literal information, LI)'와 두 개 이상의 문장에 제시되어 있는 정보를 텍스트 연결 관계에 따라 추론해야 하는 '텍스트 연결 추론(text-connecting inference, TC)' 유형은 노화로 인하여 수행 이 저하되는 반면 담화의 내용을 청자의 배경지식과 통합하여 추 론해야 하는 '빠진 정보추론(gap-filling inference, GF)' 유형의 수 행은 상대적으로 양호하다. 이러한 결과는 '상황모형(situation model)'(Radvansky, 1999) 이론으로 설명될 수 있는데, 이는 정보 처리 능력과 단기기억 등이 요구되는 상향식(bottom-up) 처리 과제 의 경우 노화로 인한 담화이해 능력의 저하가 나타나지만, 사전 지 식이나 이전의 경험이 중요한 역할을 하는 하향식(top-down) 과제 에서는 상대적으로 노화로 인한 영향이 적음을 의미한다(Jeong \& Pyun, 2005).

다음으로 담화이해는 자극을 제시하는 방법에 따라 수행력이 달라진다는 연구결과들도 존재한다. 특히, 반복해서 담화를 들려 주거나 시각적 자료를 병행하여 과제를 제시하는 것이 담화이해 수 행을 높이는 것으로 알려져 있다. 우선 일반 노인을 대상으로 한 연 구들은 담화를 반복하여 들려주는 것이 문맥(context)에 대한 정 보를 채워주기 때문에 담화이해에 효과적이라고 주장한다(Pichora-Fuller, 2008). 즉, 담화를 반복하여 들려주는 것은 다시 들음으 로써 기억흔적(memory traces)을 증가시키고, 처음 듣고 기억하지 못한 부분을 채워 복원하는 효과가 있다(Small, Kemper, \& Lyons, 1997). 이러한 '반복효과(repetition effect)'는 누적 구조 프라이밍 (cumulative structural priming) 현상으로도 설명할 수 있는데, 이 는 첫 번째 들은 정보에 반복을 통한 정보가 누적되고 이때 처음 들 은 정보가 프라이밍으로 작용하여 담화이해에 도움을 준다고 알 려져 있다(Fine \& Jaeger, 2016; Myslín \& Levy, 2016). 이러한 반복 효과는 일반 노인뿐 아니라 알츠하이머형 치매(dementia of Alzheimer's type) 환자의 언어이해에도 효과적인 것으로 알려져 있
다(Choi \& Yi, 2019; Small et al., 1997).

다음으로 그림과 같은 시각적 자료를 병행하여 담화를 들려주는 자극제시 방법의 효과는 시각자극과 청각자극을 처리하는 작업기 억의 모델과 관련이 깊다. Baddeley (2003)의 작업기억 모델에 따르 면 시각정보는 시공간적 잡기장(visuospatial sketchpad)을 통해 시 공간적 작업기억으로, 청각정보는 음운론적 회로(phonological loop)를 통해 언어적 작업기억으로 처리된다. 대체로 청각 작업기 억 과제의 수행이 시각 작업기억보다 높은 수준으로 나타나며(Gillam, Cowan, \& Marler, 1998), 작업기억에 저장되어 있는 정보를 회 상할 때 청각이 시각에 비해 우수한 것으로 알려져 있다(Penney, 1989). 그러나 시각과 청각을 통한 작업기억의 처리 단위와 용량이 서로 다르기 때문에 청각자극에 시각자극이 병행될 경우 자극이 서로 독립적으로 처리되어 보완적으로 작용할 수 있다. 더불어 청 각자극의 경우 메시지를 받아들일 만큼 충분히 집중하기 전에 사 라질 수 있으나, 시각자극이 병행된 경우 시각자극이 일정 시간 지 속되면서 주의 집중할 수 있는 기회를 충분히 제공하여 주의를 전 이하고 다시 집중하는데 필요한 시간을 허락하기 때문에 심리적으 로도 안정감을 준다고 알려져 있다(Carlson, 1996). 즉, 시각적인 자 극은 과제에 대한 흥미를 높이고 주의 집중에 도움을 주며, 추상적 인 정보를 구체화하여 조직적으로 머릿속에 저장하고 인출하는 데 도움을 준다. 또한, Pezdek과 Hodge (1999)는 기억 과제를 제시할 때는 그림자극과 언어자극을 동시에 제시하게 되면 그림자극과 언 어자극이 서로 다른 양식으로 공통의 의미를 추출하여 의미를 통 합하는데 도움을 주기 때문에 그림이나 언어 자극 중 하나를 제시 하는 것보다 그림자극과 언어자극을 동시에 제시하는 것이 더 유리 하다고 주장하였다.

이렇듯 담화를 반복하여 들여주거나 그림자극을 병행하는 등의 자극제시 방법에 따라 일반 노인의 담화이해 능력에 차이가 있다 는 연구들은 존재하지만 이러한 방법들의 효과를 비교한 연구는 제한적이다. 또한, 사실적인 정보이해와 추론과 같은 질문유형에 따라 각 담화 자극제시 방법의 효과가 다르게 나타나는지를 알아 본 연구는 존재하지 않는다. 노인들의 담화이해 능력을 높일 수 있 는 전략을 개발하고 그 효과를 검증하는 것은 임상적으로 대단히 중요하다. 따라서 본 연구에서는 일반 노인을 대상으로 담화 자극 의 제시 방법(1회 제시, 반복 제시, 그림 병행)에 따른 담화이해 능력 의 차이를 알아보고, 이러한 담화 자극제시 방법의 효과가 사실적 정보이해(LI), 텍스트 연결추론(TC) 및 빠진 정보추론(GF)의 질문 유형에 따라 다르게 나타나는지 알아보는 것을 목적으로 하였다. 


\section{연구방법}

\section{연구대상}

본 연구는 일반 노인 48 명(남성 16 명, 여성 32 명)을 대상으로 하였 다. 연구 대상자는 모국어가 한국어이며, 한국판 간이 정신상태 검 사(Korean version of Mini Mental State-Examination [K-MMSE]; Kang, 2006) 점수가 연령 및 교육정도의 규준과 비교하여 $-1 \mathrm{SD}$ (16\%ile) 이상의 정상 범주에 해당하고, 본인 보고에 의한 신경학적 질환의 병력이 없고, 한국형 노인우울검사(Geriatric Depression Scale [GDS]; Jung et al., 1997) 점수가 18점 미만으로 우울증이 없으 며, 과제 수행을 위한 시청각적 문제가 없는 자로 선정하였다. 대상 자의 성별, 연령, 교육년수와 K-MMSE 점수 평균에 대한 기술 통계 치를 Table 1에 제시하였다. 성별에 따라 연령, 교육년수, K-MMSE 점수의 유의한 차이가 있는지 알아보기 위하여 독립표본 $t$-검정을 실시한 결과 모든 변수에서 성별에 의한 차이는 유의하지 않았다.

\section{연구과제}

담화이해 과제는 Kim과 Choi (2015)의 연구에 사용한 '복날', '돌 잔치’ 이야기에 ‘여행' 이야기를 추가로 제작하여 사용하였다. 담화 의 친숙도(familiarity)가 담화이해 능력에 영향을 줄 수 있다는 기 존의 연구결과(Dubno, Ahlstrom, \& Horwitz, 2000)에 따라 본 연 구에서는 노인들에게 친숙한 에피소드와 어휘로 담화를 구성하였 다. 담화의 구성과 어휘의 적절성에 대한 내용타당도는 언어치료학 전공 교수 1 인과 국어학 전공 교수 1 인이 검증하였다. 모든 이야기는 11-12개의 문장, 평균 어절 수는 6어절이며, 한 문장의 최대 길이가 9어절을 초과하지 않도록 하였다. 담화의 구성은 이야기 문법의 하 위 범주인 배경, 계기사건, 내적 반응, 시도, 결과, 반응이 모두 포함 되도록 하였으며, 이야기를 듣고 질문에 답하는 회상(recall) 과제 를 사용하였다. 질문유형으로는 Norbury와 Bishop (2002)의 유형 에 따라 담화에 표면적으로 명시되어 있는 정보를 묻는 사실적 정 보이해(literal information, LI)', 두 개 이상의 문장에 나타난 정보 를 텍스트 연결의 관계에 따라 추론하는 '텍스트 연결추론(textconnecting inference, TC)', 담화 안에 나타난 정보를 청자의 배경 지식과 통합하여 정답을 추론하는 “빠진 정보추론(gap-filling in-

Table 1. Mean (SD) of age, education level, and K-MMSE score in participants

\begin{tabular}{lccc}
\hline & Male ( $\mathrm{N}=16)$ & Female ( $\mathrm{N}=32)$ & Total $(\mathrm{N}=48)$ \\
\hline Age (yr) & $73.93(3.25)$ & $75.93(4.50)$ & $75.27(4.20)$ \\
Education level (yr) & $9.25(3.78)$ & $6.15(3.58)$ & $7.19(3.90)$ \\
K-MMSE score & $24.87(2.27)$ & $23.59(3.35)$ & $24.02(3.08)$ \\
\hline
\end{tabular}

K-MMSE = Korean version of Mini-Mental State Examination (Kang, 2006). ference, GF)'으로 구성하였다. 질문유형에 따른 질문의 예를 Appendix 1에 제시하였다. 하나의 이야기당 세 가지의 유형별 질문 5 개씩 총 15 개의 문항이 사용되었으며, 각 문항 당 2점, 만점은 총 30 점이다. 담화이해 과제의 채점은 Kim과 Choi (2015)의 연구에 따 라 '적절한 대답', '불완전하나 적절한 대답'과 '부적절한 대답'으로 구분하고, '적절한 대답'은 2점, '적절하지만 불완전한 대답'은 1점, '부적절한 대답’은 0 점으로 하였다.

\section{연구절차}

본 연구는 나사렛대학교 생명윤리위원회(IRB)의 승인(No.181015-05)과 연구 대상자의 서면 동의를 받아 진행하였다. 연구자와 대상자는 일대일로 소음이 없는 조용한 곳에서 해당 과제를 진행 하였다. 담화이해 과제는 세 가지의 담화 과제에서의 반복효과와 순서효과를 배제하고 과제 사이의 난이도를 통제하기 위하여 역균 형화(counterbalancing)하여 6집단으로 구성하고(복날-돌잔치-여 행, 돌잔치-여행-복날, 여행-복날-돌잔치, 복날-여행-돌잔치, 돌잔 치-복날-여행, 여행-돌잔치-복날 순), 각 집단에 8 명씩 총 48 명의 대 상자가 배정되도록 하였다. 담화이해 과제 제시 방법의 순서는 모 든 대상자들에게 1 회 제시, 반복 제시, 그림 병행의 순으로 진행하 였다. 말속도는 우리말의 보통 말속도인 초당 4음절(Shin, 2018) 정 도로 제시하였으며, 반복 제시 방법은 동일한 이야기를 연속으로 두 번 들려주고, 그림 병행 방법은 이야기를 청각적으로 1 회 들려주 는 동시에 내용에 맞는 삽화 자료를 순서대로 한 장씩, 한 이야기당 5장을 제시하였다. 질문은 각 이야기를 들려준 뒤 사실적 정보이해 (LI), 텍스트 연결추론(TC)의 질문과 빠진 정보추론(GF) 순으로 진행하였다. 대상자의 반응은 모두 녹음하고 즉시 전사하였다. 담 화이해 과제 채점의 신뢰도를 평가하기 위하여 모든 자료에 대하여 두 명의 평가자 사이의 채점 일치율을 산출하였다. 제 1 평가자는 연 구자이며, 제 2 평가자는 언어병리학 석사학위 소지자이며 3 년 이상 의 언어치료 임상경력을 가진자로 하였다. 평가자 두 명의 담화이해 과제의 채점 일치율은 $95.7 \%$ 로 나타났다.

\section{통계분석}

본 연구의 모든 통계분석은 SPSS 22.0 프로그램을 사용하였다. 우선 1 회 제시, 반복 제시, 그림 병행의 자극제시 방법에 따라 담화 이해 능력에 차이가 있는지를 알아보기 위하여 반복측정 분산분 석을 실시하고, Bonferroni 방법으로 자극제시 방법의 주효과 차이 를 분석하였다. 다음으로 사실적 정보이해(LI), 텍스트 연결추론 (TC) 및 빠진 정보추론(GF)의 질문유형에 따라 자극제시 방법의 효과에 차이가 있는지 알아보기 위하여 질문유형(3)과 자극제시 
방법(3)의 혼합분산분석을 실시하고, 주효과와 상호작용 효과를 살펴보았다. 마지막으로 질문유형별로 반복 제시와 그림 병행에서 의 담화이해 수행과 일반적인 담화제시 방법인 1 회 제시에서의 총점 과의 관련성을 살펴보기 위하여 Pearson 상관분석을 실시하였다.

\section{연구결과}

\section{자극제시 방법(1회 제시, 반복 제시, 그림 병행)에 따른 노년층의 담화이해 수행의 차이}

일반 노인의 자극제시 방법에 따른 담화이해 과제의 수행은 Table 2 와 같다. 담화의 1 회 제시, 반복 제시, 그림 병행의 자극제시 방 법에 따라 담화이해 능력에 차이가 있는지를 알아보기 위하여 반 복측정 분산분석을 실시한 결과, 자극제시 방법에 따른 차이가 유 의한 것으로 나타났다 $(F=69.604, p<.001)$. 주효과 비교 결과 1 회 제시와 반복 제시 $(p<.001), 1$ 회 제시와 그림 병행 $(p<.001)$ 사이에 는 유의한 차이가 있었지만, 반복 제시와 그림 병행의 경우 차이가 유의하지 않았다. 즉, 1 회 제시(62.5\%)에 비해 반복 제시(75.6\%)와 그림 병행(75.2\%)의 경우 담화이해 점수가 유의하게 높았으나, 반 복 제시와 그림 병행 방법 사이에 유의한 차이는 없었다.

\section{질문유형에 따른 자극제시 방법 효과의 차이}

사실적 정보이해(LI), 텍스트 연결추론(TC) 및 빠진 정보추론 (GF)의 질문유형에 따른 1 회 제시, 반복 제시, 그림 병행의 자극제 시 방법에서의 담화이해 점수를 Table 3 에, 수행률을 Figure 1에 제 시하였다. 다음으로 사실적 정보이해(LI), 텍스트 연결추론(TC), 빠진 정보추론(GF)의 질문유형에 따라 자극제시 방법의 효과에 차이가 있는지 알아보기 위하여 질문유형(3)과 자극제시 방법(3)의 혼합분산분석을 실시하였다. 분석 결과, 질문유형 $(F=82.653$, $p<.001)$ 과 자극제시 방법 $(F=32.190, p<.001)$ 의 주효과가 모두 유

Table 2. Mean (SD) of scores for stimulus presentation methods on discourse comprehension

\begin{tabular}{cccc}
\hline & Once & Twice & With pictures \\
\hline Discourse comprehension score & $19.39(3.18)$ & $22.70(3.43)$ & $22.58(3.16)$
\end{tabular}

Table 3. Mean (SD) of scores for stimulus presentation methods on discourse comprehension by question type

\begin{tabular}{lccc}
\hline Question type & Once & Twice & With pictures \\
\hline LI & $6.33(1.66)$ & $7.66(1.29)$ & $7.16(1.47)$ \\
TC & $4.77(1.61)$ & $6.14(1.85)$ & $6.66(1.73)$ \\
GF & $8.39(1.26)$ & $8.97(1.39)$ & $8.72(1.21)$ \\
\hline
\end{tabular}

$\mathrm{LI}=$ literal information; $\mathrm{TC}=$ text-connecting inference; $\mathrm{GF}=$ gap-filling inference.
의하였으며, 질문유형과 자극제시 방법 사이의 상호작용 효과 $(F=5.329, p<.001)$ 도 유의한 것으로 나타났다. 사후 분석 결과 질 문유형별 차이를 살펴보면 모든 자극제시 방법에서 빠진 정보추론 (GF), 사실적 정보이해(LI), 텍스트 연결추론(TC)의 순으로 담화이 해 수행이 높은 것으로 나타났으며, 세 가지 질문유형에 따른 차이 가 모두 유의하였다 $(p<.001)$. 다음으로 1 번 제시, 반복 제시, 그림 병행의 자극제시 방법에 따른 차이는 1 번 제시와 반복 제시, 1 번 제 시와 그림 병행 사이의 차이는 유의하였으나, 반복 제시와 그림 병 행 사이의 차이는 유의하지 않은 것으로 나타났다. 질문유형과 자 극제시 방법 사이의 상호작용 효과는 반복 제시의 경우 1 회 제시에 비해 사실적 정보이해(LI)의 점수가 가장 많이 증가한 반면, 그림 병행의 경우 텍스트 연결추론(TC)의 점수가 가장 많이 증가한 것 과 관련이 있었다.

\section{자극제시 방법에 따른 질문유형별 담화이해 점수의 상관}

담화의 자극제시 방법에 따른 담화이해 점수의 관련성을 살펴보 기 위하여 일반적인 담화 자극제시 방법인 담화를 1 회 제시했을 때 의 담화이해 총점과 반복 제시, 그림 병행 시의 질문유형별 담화이 해 점수 및 총점의 Pearson 상관분석을 실시하고 그 결과를 Table 4 에 제시하였다. 상관분석 결과 1 회 제시했을 때의 담화이해 총점과

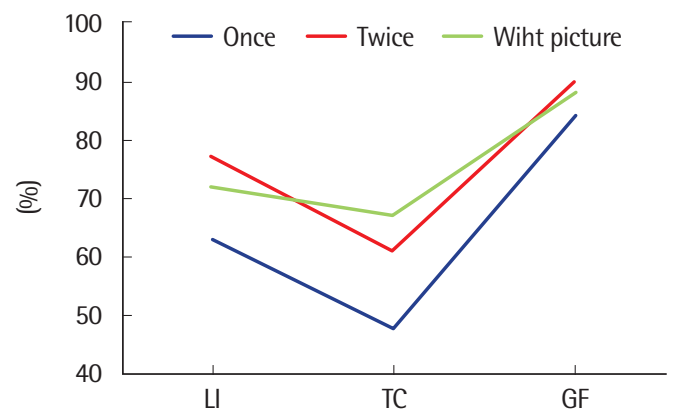

Figure 1. Percentage of correct answers to discourse comprehension tasks according to stimulus presentation method and question type.

$\mathrm{LI}=$ literal information; $\mathrm{TC}=$ text-connecting inference; $\mathrm{GF}=$ gap-filling inference.

Table 4. Result of correlation of discourse comprehension scores on stimulus presentation method by question type

\begin{tabular}{|c|c|c|c|c|c|c|c|c|}
\hline & \multicolumn{4}{|c|}{ Twice } & \multicolumn{4}{|c|}{ With picture } \\
\hline & LI & TC & GF & Total & LI & TC & GF & Total \\
\hline $\begin{array}{l}\text { Total discourse } \\
\text { comprehension } \\
\text { score in telling } \\
\text { a story once }\end{array}$ & $.316^{*}$ & $.368^{*}$ & 0.179 & $.456^{* *}$ & $.537^{* *}$ & $.538^{* *}$ & 0.253 & $.652^{* *}$ \\
\hline
\end{tabular}

$\mathrm{LI}=$ literal information; $\mathrm{TC}=$ text-connecting inference; $\mathrm{GF}=$ gap-filling inference. ${ }^{*} p<.05,{ }^{* *} p<.01$. 
반복 제시, 그림 병행 시의 질문유형별 담화이해 점수 및 총점의 상관 은 빠진 정보추론(GF)을 제외하고는 모두 유의한 것으로 나타났다.

\section{논의 및 결론}

본 연구에서는 일반 노인을 대상으로 담화의 자극제시 방법(1회 제시, 반복 제시, 그림 병행)에 따른 담화이해 능력의 차이를 알아 보고, 이러한 담화 자극제시 방법이 담화이해 향상에 미치는 효과 가 질문유형에 따라 다르게 나타나는지 알아보았다. 결과를 구체 적으로 살펴보면, 첫째 담화 자극제시 방법에 따라 담화이해 점수 에 유의한차이가 나타났는데, 담화의 반복 제시, 그림 병행 방법 모 두 담화를 1 회 제시한 것에 비해 담화이해 점수가 유의하게 높았으 며, 반복 제시와 그림 병행 사이의 차이는 유의하지 않았다. 우선 반 복은 여러 연구들에서 노인들의 청각적 이해력을 높이는 전략으로 알려져 있다(Budar, 2010). 이러한 반복의 효과는 서론에서 언급했 듯이 기억흔적(memory trace)을 강화시키고(Cervantes \& Gainer, 1992), 첫 번째 들었던 청각적 자극이 누적 구조 프라이밍(cumulative structural priming)으로 작용하여 언어이해 능력과 이해 속도 를 높이는 역할을 한다(Choi \& Yi, 2019; Fine \& Jaeger, 2016; Myslín \& Levy, 2016). 또한, 청각적 정보 입력 과정에서의 내현적 시연 (subvocal rehearsal)을 통한 연습(Baddeley, 2003)과, 반복을 통한 청각적 입력강화(auditory input enhancement)로 인한 단기기억 및 작업기억의 활성화가 언어이해에 긍정적인 영향을 미침을 알 수 있다(Choi \& Yi, 2019; Kim \& Ha, 2019). 청각적 반복을 통한 언어 이해 능력의 향상은 일반 노인 이외에 지적장애 아동(Kim, 2012) 및 학령기 아동(Cervantes \& Gainer, 1992; Mares, 2006) 등과 알츠 하이머형 치매 환자들(Choi \& Yi, 2019; Small et al., 1997)에서도 나타났다. 다음으로 그림 병행으로 인한 담화이해 효과 역시 유의 한 것으로 나타났는데, 흥미로운 것은 그림을 병행하여 담화를 제 시한 경우 반복해서 담화를 들려주는 방법만큼 효과적이었다는 것이다. 청각자극에 시각자극이 병행될 경우 서로 다른 양식이 독 립적으로 처리되어 공통의 의미를 이중으로 추출할 뿐 아니라(Pezdek \& Hodge, 1999), 순간적으로 지나가는 청각 정보의 기억부담 을 시각 정보가 보완함으로써 흥미와 주의 집중력을 높이고, 언어 및 추상적인 정보에 대해 구체적이고 조직적으로 머릿속에 저장하 고 인출하는 데 도움을 준다. 지금까지 그림 자극과 같은 시각자극 을 제시하였을 때의 언어 능력 향상과 관련된 연구는 다양하게 이 루어져 왔는데, 아동들의 경우 그림을 병행하여 담화를 들려주었 을 때 이야기 산출 능력이 향상되었으며(Schneider \& Dubé, 2005), 일반 노인의 경우 동사 이름대기(Choi \& Sung, 2014)에서, 알츠하이
머형 치매 환자의 경우 받아쓰기(Sung, 2010)에서 그림이 병행되었 을 때 수행이 향상되었다. 또한 Lee, Kang과 Son (2007)은 알츠하이 머형 치매 환자를 대상으로 한 연구에서 그림과 사진 자극을 제시 한 경우 이야기 회상 과제의 수행이 향상되었다고 보고하였다.

둘째, 질문유형에 따라 자극제시 방법의 효과에 차이가 있는지 를 분석한 결과, 질문유형과 자극제시 방법의 주효과가 모두 유의 하였으며, 질문유형과 자극제시 방법 사이의 상호작용 효과 또한 유의한 것으로 나타났다. 우선, 질문유형별 차이를 살펴보면 모든 자극제시 방법에서 빠진 정보추론(GF), 사실적 정보이해(LI), 텍스 트 연결추론(TC)의 순으로 담화이해 점수가 높게 나타났으며, 세 가지 질문유형에 따른 차이가 모두 유의하였다. 이러한 차이는 유 사한 과제를 사용한 담화이해 연구와 동일한 결과로, 담화에 표면 적으로 명시되어 있는 정보를 이해해야 하는 사실적 정보이해(literal information, LI)'와 담화안에 분리되어 있는 정보를 텍스트 연 결 관계에 따라 추론해야 하는 '텍스트 연결추론(text-connecting inference, TC)' 유형은 노화로 인하여 수행이 저하되는 반면 담화 의 내용을 청자의 배경지식과 통합하여 추론해야 하는 '빠진 정보 추론(gap-filling inference, GF)' 유형의 경우 상대적으로 수행이 양호함을 알 수 있다(Choi, 2016; Kim \& Choi, 2015). 이러한 질문 유형에 따른 담화이해 수행의 차이는 1 회 제시, 반복 제시, 그림 병 행 제시의 모든 조건에서 동일한 것으로 나타났다. 다음으로 담화 자극의 제시 방법에 따른 차이를 살펴보면 1 번 제시와 반복 제시, 1 번 제시와 그림 병행 사이의 차이는 유의하였으나, 반복 제시와 그 림 병행 사이의 차이는 유의하지 않은 것으로 나타났다. 이는 반복 제시와 그림 병행의 자극제시 방법이 일반 노인의 담화이해 능력 향상에 모두 효과적이며, 두 방법의 효과는 유사함을 알 수 있다. 질문유형과 자극제시 방법 사이의 상호작용 효과 역시 유의한 것 으로 나타났는데, 이는 반복 제시의 경우 1 회 제시에 비해 사실적 정보이해(LI)의 점수가 가장 많이 증가한 반면, 그림 병행의 경우 텍 스트 연결추론(TC)의 점수가 가장 많이 증가한 것과 관련이 있음 을 유추할 수 있다. 이는 담화의 표면적인 정보에 대한 이해를 향상 시키기 위해서는 담화를 반복적으로 제시하는 것이 더 효과적이 며, 텍스트 사이의 연결 및 통합을 위한 논리적 추론의 향상을 위해 서는 시각적인 자료를 병행하는 것이 더 효과적이라는 것을 시사한 다. 질문유형에 따른 담화이해 수행에 미치는 자극제시 방법의 차 이를 질문유형별로 보다 구체적으로 살펴보면 다음과 같다. 첫째, 사실적 정보이해(LI)의 경우 담화 안에서의 개별 단어와 문장의 언 어처리, 단기기억 및 회상, 처리 속도와 관련이 깊다(Choi, 2015; Wegner, Brookshire, \& Nicholas, 1984). 따라서 반복해서 담화를 들려줄 경우 처음에 들었을 때 처리되지 못한 정보를 다시 들음으 
로써 노화로 인한 언어 및 단기기억 능력의 한계를 효율적으로 보 완할 수 있음을 알 수 있다. 둘째, 텍스트 연결추론(TC)은 담화 정 보의 텍스트 기반(text-based)의 상향식(bottom-up) 처리를 기초 로 하지만 담화 안에 제시된 사실적인 정보 이해와 더불어 담화 안 의 정보를 연결하고, 통합해야 하는 질문유형으로(Johnson, 2003), 단기기억 및 언어 능력 이외에 작업기억이나 집행기능과 같은 다소 고차원적인 인지를 요구한다(Choi, 2015; Gernsbacher, Varner, \& Faust, 1990; McKoon \& Ratcliff, 1992). 따라서 시각과 청각의 이중 양식을 통한 언어 및 추상적인 정보를 조직적으로 저장하고 인출 하는 데 도움을 주는 그림 병행 방법이 텍스트 연결추론(TC) 질문 유형 수행에 긍정적인 영향을 미쳤을 것으로 여겨진다. 셋째, 빠진 정보추론(GF) 질문유형은 담화의 내용을 일반 지식이나 경험을 통 하여 하향식(top-down)으로 추론해야 하는 유형이다(Van Dijk, 1977). 이러한 빠진 정보추론(GF)의 경우 담화에서 제시된 정보보 다는 스크립트 구조(script structure)에 이미 정형화된 도식(sche$\mathrm{ma}$ )을 활용하기 때문에(Cho et al., 2003), 자극제시 방법에 따른 영 향을 거의 받지 않는다고 생각할 수 있다.

마지막으로 담화의 자극제시 방법에 따른 담화이해 점수의 관련 성을 살펴보기 위하여 일반적인 담화제시 방법인 담화를 1 회 제시 했을 때의 담화이해 총점과 반복 제시, 그림 병행 시의 질문유형별 담화이해 점수 및 총점의 상관분석 결과 담화이해 총점과 반복 제 시, 그림 병행 시의 질문유형별 담화이해 점수 및 총점의 상관은 빠 진 정보추론(GF)을 제외하고는 모두 유의한 것으로 나타났다. 이 는 앞에서도 언급했듯이 담화이해가 고차원적인 인지기능을 요구 하는 과제이며 따라서 반복 제시나 그림 병행과 같은 인지적 전략 을 통한 과제 수행의 효과가 서로 관련이 있음을 시사한다.

본 연구에서는 일반 노인을 대상으로 담화의 자극제시 방법에 따른 담화이해 능력의 차이를 알아보고, 이러한 담화 자극제시 방 법의 효과가 질문유형에 따라 어떻게 다르게 나타나는지 알아보았 다. 노인들의 담화이해 능력을 향상시키기 위한 전략들을 객관적 으로 비교하고, 질문유형에 따라 효과적인 자극제시 방법에 차이 가 있다는 점을 밝힌 점은 본 연구의 임상적 의의로 들 수 있다. 그 러나 다양한 담화의 유형, 길이, 복잡성 등에 따른 담화이해 능력 및 자극제시 방법에 대한 차이 등을 살펴보지 못한 점, 일반 노인들 의 연령에 따른 차이를 알아보지 못함 점 등이 아쉬움으로 남는다. 앞으로 이러한 내용을 보완한 후속연구가 진행되기를 바란다.

\section{REFERENCES}

Baddeley, A. (2003). Working memory and language: an overview. Journal of
Communication Disorders, 36(3), 189-208.

Burda, A. (2010). Communication and swallowing changes in healthy aging adults. Burlington, MA: Jones and Bartlett Learning.

Carlson, J. K. (1996). Teaching children with autism: strategies to enhance communication and socialization. Focus on Autism and Other Developmental Disabilities, 11(4), 254-255.

Cervantes, R., \& Gainer, G. (1992). The effects of syntactic simplification and repetition on listening comprehension. TESOL Quarterly, 26(4), 767-770.

Cho, M. H., Lee, J. M., Kim, J. O., Shin, H. J., Lee, K. O., Doh, K. S., Lee, Y., Lee, H. J., Kim, Y. J., Kim, S. Y., Koh, S. R., \& Jung, H. S. (2003). Psychology of language. Seoul: Hakjisa.

Choi, H. (2015). The relationship between executive function and story comprehension by question type in healthy elderly adults. Journal of SpeechLanguage and Hearing Disorders, 24(3), 1-13.

Choi, H. (2016). Working memory and verbal memory's relationship to discourse comprehension in patients with amnestic mild cognitive impairment and with Alzheimer's disease. Communication Sciences \& Disorders, 21(2), 324-332.

Choi, H., \& Yi, B. (2019). Effects of syntactic complexity and sentence repetition on sentence comprehension in patients with dementia of Alzheimer's type. Communication Sciences \& Disorders, 24(4), 986-995.

Choi, S. J., \& Sung, J. E., (2014). Task-specific and argument structure effects on verb production in normal elderly adults: animation vs. picture comparisons. Journal of Rehabilitation Research, 18(4), 279-298.

Dubno, J. R., Ahlstrom, J. B., \& Horwitz, A. R. (2000). Use of context by young and aged adults with normal hearing. The Journal of the Acoustical Society of America, 107(1), 538-546.

Ferstl, E. C., Walther, K., Guthke, T., \& von Cramon, D. Y. (2005). Assessment of story comprehension deficits after brain damage. Journal of Clinical and Experimental Neuropsychology, 27(3), 367-384.

Fine, A. B., \& Jaeger, T. F. (2016). The role of verb repetition in cumulative structural priming in comprehension. Journal of Experimental Psychology: Learning, Memory, and Cognition, 42(9), 13-62.

Gernsbacher, M. A., Varner, K. R., \& Faust, M. E. (1990). Investigating differences in general comprehension skill. Journal of Experimental Psychology: Learning, Memory, and Cognition, 16(3), 430-445.

Gillam, R. B., Cowan, N., \& Marler, J. A. (1998). Information processing by school-age children with specific language impairment: evidence from a modality effect paradigm. Journal of Speech, Language, and Hearing Research, 41(4), 913-926. 
Jeong, H., \& Pyun, J. Y., (2005). Recall and interpretation of narrative texts in college students, middle-aged, and older adult groups. Korean Journal of Cognitive and Biological Psychology, 17(4), 509-527.

Johnson, R. E. (2003). Aging and the remembering of text. Developmental Review, 23(3), 261-346.

Jung, I. K., Kwak, D. I., Shin, D. K., Lee, M. S., Lee, H. S., \& Kim, J. Y. (1997). A reliability and validity study of geriatric depression scale. Journal of Korean Neuropsychiatric Association, 36(1), 103-112.

Kang, Y. W. (2006). A normative study of the Korean-Mini Mental State Examination (K-MMSE) in the elderly. Korean Journal of Psychology, 25(2), $1-12$.

Kemper, S. (2006). Language in adulthood. In E. Bialystok \& F. I. M. Craik (Eds.), Lifespan cognition. New York, NY: Oxford University Press.

Kim, M. J., \& Ha, J. W. (2019). Effects of vocal rehearsal and auditory input enhancement on delayed nonword repetition performance in children with and without speech sound disorders. Communication Sciences \& Disorders, $24(1), 101-116$.

Kim, J., \& Kim H. (2009). Communicative ability in normal aging: a review. Korean Journal of Communication \& Disorders, 14(4), 495-513.

Kim, Y. J., \& Choi, H. (2015). Story comprehension abilities by question types using recall task in young and older Adults. Journal of Rehabilitation Research, 19(3), 195-213.

Kim, E. (2012). The effect of repeated reading of picture story book on language expression and story comprehension of children with mental retardation (Master's thesis). Seoul National University of Education, Seoul, Korea.

Lee, S. H., Kang, S. K., \& Son, E. N. (2007). The effect of story-recall training programing using newspaper on the language comprehension ability of elderly people with Alzheimer's disease patients dementia. Journal of Speech and Hearing Disorders, 16(1), 55-73.

Lee, S. J., Lee, S. J., Song, J. Y., \& Kim, H. H. (2014). Characteristics of language comprehension in normal elderly and the mild cognitive impaired. Dementia and Neurocognitive Disorders, 13(3), 51-62.

Light, L. L. (1991). Memory and aging: four hypotheses in search of data. Annual Review of Psychology, 42(1), 333-376.

Little, D. M., Prentice, K. J., Darrow, A. W., \& Wingfield, A. (2005). Listening to spoken text: adult age differences as revealed by self-paced listening. Experimental Aging Research, 31(3), 313-330.

Mares, M. L. (2006). Repetition increases children's comprehension of television content-up to a point. Communication Monographs, 73(2), 216-241. McKoon, G., \& Ratcliff, R. (1992). Inference during reading. Psychological
Review, 99(3), 440-466.

Myslín, M., \& Levy, R. (2016). Comprehension priming as rational expectation for repetition: evidence from syntactic processing. Cognition, 147, 2956.

Norbury, C. F., \& Bishop, D. V. M. (2002). Inferential processing and story recall in children with communication problems: a comparison of specific language impairment, pragmatic language impairment and high-functioning autism. International Journal of Language and Communication Disorders, 37(3), 227-251.

Penney, C. G. (1989). Modality effects and the structure of short-term verbal memory. Memory and Cognition, 17(4), 398-422.

Pezdek, K., \& Hodge, D. (1999). Planting false childhood memories in children: the role of event plausibility. Child Development, 70(4), 887-895.

Pichora-Fuller, M. K. (2008). Use of supportive context by younger and older adult listeners: balancing bottom-up and top-down information processing. International Journal of Audiology, 47(2), S72-S82.

Radvansky, G. A. (1999). Memory retrieval and suppression: the inhibition of situation models. Journal of Experimental Psychology: General, 128(4), 563-579.

Schaie, K. W., \& Willis, S. L. (2010). Handbook of the psychology of aging (7th Ed.). San Diego, CA: Elsevier.

Schneider, P., \& Dubé, R. V. (2005). Story presentation effects on children's retell content. American Journal of Speech-Language Pathology, 14(1), 5260.

Shin, J. (2018). Breath and memory in speech based on quantitative analysis of breath groups and pause units in Korean. Korean Linguistics, 79, 91-116.

Small, J. A., Kemper, S., \& Lyons, K. (1997). Sentence comprehension in Alzheimer's disease: effects of grammatical complexity, speech rate, and repetition. Psychology and Aging, 12(1), 3-11.

Son, E. N., \& Kang, S. K., (2006). A study on story retelling in the adults. Journal of Speech and Hearing Disorders, 15(1), 71-85.

Sparks, J. R. (2012). Language, discourse comprehension and understanding. New York, NY: Springer.

Stubbs, M. (1983). Discourse analysis: the sociolinguistic analysis of natural language. Chicago, IL: University of Chicago Press.

Sung, S. H. (2010). Writing disorders in Alzheimer's disease: exploring the effect of word characteristics and type of stimulus (Master's thesis). Ewha Woman's University, Seoul, Korea.

Van Dijk, T. A. (1977). Semantic macro-structures and knowledge frames in discourse comprehension. In M. A. Just \& P. Carpenter (Eds.), Cognitive 


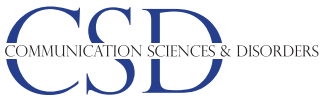

processes in comprehension. New York, NY: Psychology Press.

Wegner, M. L., Brookshire, R. H., \& Nicholas, L. E. (1984). Comprehension
노인의 담화 이해・ 송제호 외

of main ideas and details in coherent and noncoherent discourse by aphasic and nonaphasic listeners. Brain and Language, 21(1), 37-51. 
JeHo Song, et al. • Discourse Comprehension in Older People

Appendix 1. 담화이해 과제(여행이야기)의 질문유형별 예

\begin{tabular}{lll}
\hline 질문유형 & \multicolumn{1}{c}{ 질문 } & \multicolumn{1}{c}{ 정답 } \\
\hline 사실적 정보이해 & 누가 지갑을 보관하고 있었나요? & 역무원 \\
텍스트 연결추론 & 할머니는 왜 가방을 열었나요? & 음료수를 사려고 \\
빠진 정보추론 & 이 이야기의 계절은 언제라고 생각하세요? & 가을 \\
\hline
\end{tabular}




\section{국문초록}

\section{자극제시 방법이 노인의 담화이해에 미치는 영향}

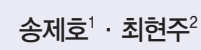

1불당하나365클리닉, ${ }^{2}$ 나사렛대학교 언어치료학과

배경 및 목적: 노인의 담화이해 능력은 자극제시 방법에 따라 달라질 수 있음에도 불구하고 관련 연구는 제한적이다. 본 연구에서는 일 반 노인을 대상으로 담화의 자극제시 방법에 따른 담화이해 능력의 차이를 알아보고, 담화 자극제시 방법의 효과가 사실적 정보나 추 론과 같은 질문유형에 따라 다르게 나타나는지 알아보는 것을 목적으로 하였다. 방법: 본 연구는 일반 노인 48 명을 대상으로 하였다. 담 화 과제는 이야기를 듣고 질문에 답하는 회상과제를 사용하였으며, 1 회 제시, 반복 제시, 그림 병행의 자극제시 방법을 사용하였다. 질 문유형은 사실적 정보이해, 텍스트 연결추론 및 빠진 정보추론으로 구성하였다. 결과: 첫째, 담화의 반복 제시, 그림 병행 방법 모두 1 회 제시에 비해 담화이해 점수가 높았으며, 반복 제시, 그림 병행 사이의 차이는 유의하지 않은 것으로 나타났다. 둘째, 사실적 정보이해의 경우 반복에서의 수행이 가장 높은 반면, 텍스트 연결추론의 경우 그림 병행의 수행이 가장 높았다. 셋째, 빠진 정보추론의 경우 자극제 시 방법에 따른 담화이해 능력의 차이가 유의하지 않았다. 논의 및 결론: 이러한 결과는 일반 노인을 대상으로 담화의 표면적인 정보이 해 향상을 위해서는 담화를 반복적으로 제시하는 것이 더 효과적이며, 텍스트 사이의 연결 및 통합을 위한 논리적 추론의 향상을 위해 서는 시각적인 자료를 병행하는 것이 더 효과적이라는 것을 시사한다.

핵심어: 담화이해, 자극제시 방법, 반복, 그림 병행 제시

본 연구는 제 1 저자의 석사학위논문을 수정 및 보완하였음.

\section{참고문헌}

강연욱(2006). K-MMSE (Korean-Mini Mental State Examination)의 노인 규준 연구. 한국심리학회지, 25(2), 1-12.

김미진, 하지완(2019). 외현적 시연과 청각적 입력 강화가 말소리장애 아동의 지연 비단어 따라말하기 수행력에 미치는 영향. Communication Sciences \& Disorders, 24(1), 101-116.

김정완, 김향희(2009). 노년층 의사소통 능력에 대한 문헌 연구. 언어청각장애연구, 14(4), 495-513.

김은아(2012). 그림이야기책 반복 읽어주기가 정신지체아동의 언어표현 및 이야기 이해에 미치는 영향. 서울교육대학교 대학원 석사학위 논문. 김은지, 최현주(2015). 회상과제를 통한 청년과 노인의 질문유형별 이야기 이해 특성. 재활복지, 19(3), 195-213.

손은남, 강수균(2006). 청년기와 노년기의 이야기 담화 능력 특성 연구. 언어치료연구, 15(1), 71-85.

성소현(2010). 자극제시 유형과 어휘특성에 따른 알츠하이머치매 환자의 단어쓰기 능력. 이화여자대학교 대학원 석사학위 논문. 신지영(2018). 언어수행에서의 호흡과 기억. 한국어학, 79, 91-116.

이성호, 강수균, 손은남(2007). 신문을 활용한 회상 프로그램이 알츠하이머형 치매인의 언어이해력에 미치는 효과. 언어치료연구, 16(1), 55-73.

이수정, 이승진, 송지연, 김향희(2014). 정상 노년층과 경도인지장애의 언어 이해력 특성. 대한치매학회지, 13(3), 51-62.

정인과, 곽동일, 신동균, 이민수, 이현수, 김진영(1997). 노인우울척도(Geriatric Depression Scale)의 신뢰도, 타당도 연구. 신경정신의학, 36(1), 103-

112.

정혜선, 편지영(2005). 대학생, 중년, 노인 집단의 이야기에 대한 기억과 해석. 한국심리학회지: 인지 및 생물, 17(4), 509-527. 조명한, 이정모, 김정오, 신현정, 이광오, 도경수, 이양, 이현진, 김영진, 김소영, 고성룡, 정혜선(2003). 언어심리학, 서울: 학지사. 최수진, 성지은(2014). 과제 제시 유형 및 논항 수에 따른 노년층의 동사 이름대기 수행력 차이. 재활복지, 18(4), 279-293. 최현주(2015). 질문 유형에 따른 고령자의 이야기 이해 능력과 집행기능과의 상관. 언어치료연구, 24(3), 1-13.

최현주(2016). 기억상실형 경도인지장애와 알츠하이머병 환자의 이야기 이해 능력과 작업기억 및 언어기억의 상관. Communication Sciences \& Dis- 
JeHo Song, et al. • Discourse Comprehension in Older People

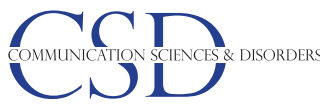

orders, 21(2), 324-332.

최현주, 이봉원(2019). 알츠하이머형 치매 환자의 문장이해 능력에 구문적 복잡성과 문장 반복이 미치는 영향. Communication Sciences \& Disorders, 24(4), 986-995.

\section{ORCID}

송제호(제1저자, 언어재활사 https://orcid.org/0000-0002-1001-0224); 최현주(교신저자, 교수 https://orcid.org/0000-0003-4654-3206) 